\title{
Measuring Impact in the Digital Age
}

\author{
Darshana T. Shah, PhD'
}

\section{KEYWORDS}

Impact Factors

One of the many challenges faced by academic faculty is identifying the impact of their scholarly contributions on their respective disciplines.

Traditionally, bibliometric measures such as the journal impact factor have been utilized to calculate the impact of scholarly communication. The journal impact factor is a popular metric used to demonstrate a journal's scope. It came into use during the 1950s through the work of Eugene Garfield, ${ }^{1}$ who devised the citation metric to help librarians prioritize purchases of important journals and illuminate a journal's overall performance. The journal impact factor is also used to gauge the academic accomplishment of an individual author. This assessment is frequently determined by a promotion and tenure committee and can impact an individual's rise through the academic ranks. It is also used by funding agencies to determine an individual's academic achievement and is important for institution-level evaluations conducted by university and medical school accreditation agencies.

It is now widely recognized that the impact factor has become less relevant, as it relies on the correlation of the number of citations received by manuscripts published by the journal during a specific timeperiod of interest, and is therefore not a fair metric to apply to individuals when measuring the impact of scholarly work. ${ }^{2}$ This is of particular importance in the modern era, as journals are now increasingly taking their enterprises into the digital world. Whereas manuscripts were previously bound in a physical journal, along with the other articles contained in that issue, works can now be identified and accessed individually online.

Today, there has been an increase in usage of alternative metrics to measure scholarly impact. This has been shaped by the rise of open access, peer-reviewed journals and open data movements ${ }^{3}$, which share a common goal of transforming the current state of higher education and research by utilizing 21 st-century tools, such as digital technology and social media. ${ }^{4}$ This has resulted in scholarly publishing offering numerous ways to increase the discoverability of individual articles and to improve knowledge transfer leading to emergence of alternative factors of impact. 
Emerging strategies of measuring author-level metrics and impact suggest complementing the journal's impact factor with social media engagement. Using social media to engage an audience in meaningful conversations can create measurable impact. Additionally, creating and maintaining an online authors' profile on Google Scholar, and using persistent identifiers such as $\mathrm{ORCID}^{5}$, enable an author to create a profile that is unique and distinguishable from other researchers. The integration of vital research workflows such as manuscript and grant submission will support automated linkages between an author and their professional activities and ensure recognition of work. As authors move toward taking a more active role in establishing their online research presence, it is imperative that relevant impact metrics are developed and utilized to measure impact in the digital age accurately.

\section{AUTHOR AFFILIATIONS}

1. Marshall University Joan C. Edwards School of Medicine, Huntington, West Virignia

\section{REFERENCES}

1. Garfield E. The history and meaning of the journal impact factor. Journal of the American Medical Association. 2006;295(1);90-93.

2. Pierot $L$, Krainik A. Journal impact factor: does it have an impact? Journal of Neuroradiology. 2015;42(5):253-254.

3. Holly Else. Radical open-access plan could spell end to journal subscriptions. Nature. 2018. https://www.nature.com/articles/d41586-01806178-7

4. Loomba RS, Anderson RH. Are we allowing impact factor to have too much impact: the need to reassess the process of academic advancement in pediatric cardiology? Congenital Heart Disease. 2018;13(2)163-166.

5. Orcid 